can be understood on the ground of the compositional variation and different cation arrangement connected with the intensive parameters change during the crystallization process. Recent studies of cation site partitioning in Tirich $1 M$ polytype from Black Hill (Australia) using a multi-technical approach [1] showed the occurrence of $\mathrm{Fe}$, as $\mathrm{Fe}^{2+}$ and $\mathrm{Fe}^{3+}$, and $\mathrm{Ti}$, as $\mathrm{Ti}^{3+}$ and $\mathrm{Ti}^{4+}$. While Titanium populates both octahedral and tetrahedral site, $\mathrm{Fe}$ is located only at the octahedral position. In addition $\mathrm{Mg}$ and $\mathrm{Fe}$ distribution was shown to be shared out in approximately equal amounts across M1 and M2 site.

The present study investigates the $2 M_{1}$ polytype coexisting with $1 M$ form, from Black Hill. Structural analysis showed similar M1 and M2 cation distribution in both polytypes with some noteworthy differences regarding occupancy of the octahedral cations. More specifically, while $\mathrm{Mg}$ and $\mathrm{Fe}$ randomly populate both $\mathrm{M} 1$ and $\mathrm{M} 2$ site in the $1 M$ polytype, these cations are distributed in orderly manner in the $2 M_{1}$ polytype, resulting in symmetry change from $C 2 / \mathrm{m}(1 M)$ to $C 2 / \mathrm{c}\left(2 M_{1}\right)$ as well as $c$ parameter doubling. This work also investigates an apparent polytype, observed in the trioctahedral micas from Alto Paranaibo igneous province (Southeastern Brazil). Crystal chemistry of $1 M$ polytype from this locality was investigated by [2]. By making use of the multitechnical approach, [3] recently reanalysed one of the sample quoted in [2] and labelled Ma1. A number of interesting new results were found: $\mathrm{Na}$ is lodged at octahedral site, $\mathrm{Ti}$ at both octahedral and tetrahedral sites and all $\mathrm{Fe}^{3+}$ at tetrahedral site and $\mathrm{Fe}^{2+}$ populating the same octahedral site. Further investigations showed that the Mal can also form apparent polytypes, i.e. twinnings of $1 M$ polytype which simulate diffraction of polytype patterns with long periodicity $(\mathrm{c} \approx 30 \AA)$. Structure refinement of the twinned crystal $(\mathrm{R}=3.9 \%$, carried out on the family reflections) indicated that the twin law is [310], the twin index is 3 and the volume element ratio is roughly $0.85: 0.09: 0.06$. The same conclusions were reached by [4] when studying ferric phlogopites from Ruiz Peak (Northern Chile).

[1] Schingaro E., Scordari F., Mesto E., Brigatti M. F. and Pedrazzi G. (2005) Clay and Clay Minerals, 2, 179-189.

[2] Brigatti M. F., Medici L., Poppi L. and Vaccaio C. (2001) The Canadian Mineralogist, 39, 1333-1345.

[3] Sabato A., Scordari F., Brigatti M. F. (2006) XXXV Congresso Nazionale A.I.C., Ferrara

[4] Nespolo M. and Yoshihiro K. (2001) Eur. J. Mineral., 13, $1047-1056$

\section{MS41 P16}

The influence of anthropogenic salinization on the soil mineralogy Yulia S.Simakova, Institute of Geology KomiSC RAS, Syktyvkar, Russia.

E-mail: cryst@geo.komisc.ru

Keywords: crystal chemistry of clays transformation layer silicates, mineral characterization as soil components

The objects of our investigation are the soils from the Seriogovo salt plug territory where salt mineral waters deposites are situated. Seriogovo salt plug is confined to Mezen syneclise of Russian platform.

Samples were obtained from 7 soil cross sections near the Seryogovo salt deposite: R-4, R-6, R-7, PR-1 uncontaminated (background) and R-5, R-8, R-9 - saline cross sections at the depth $0-103 \mathrm{~cm}$. Soil-forming rocks at this sections are morainic loams underlying by sandstones.
The mineralogical composition of the clay fraction $(<2$ $\mu \mathrm{m})$ of samples was determined by x-ray diffractometry. The $d(060)$-values were used to distinguish dioctahedral $(1.510 \AA)$ and trioctahedral $(1.538 \AA)$ minerals.

$\mathrm{X}$-ray analysis indicates that almost all clay samples of background sections contain smectite, illite, chlorite, kaolinite with dominated smectite. In clay samples of saline soils chlorite, vermiculite, interstratified chlorite/vermiculite, kaolinite, illite and galite are contained. Chlorite became the predominant 14- $\AA$ mineral. We can propose that interlayer octahedral layers are more stable than exchangeable cations of clay minerals' crystal structure in the saline environment.

The XRD patterns for the clay fraction of the uncontaminated section has an intense peak of $1.540 \AA$ and a smaller peak of $1.507 \AA$ suggesting that in this samples trioctahedral minerals are dominated, but also samples contains some dioctahedral minerals. The samples of the saline section also has both trioctahedral and dioctahedral minerals but the intensity of the peak for the dioctahedral mineral, however, is proportionally larger than in the uncontaminated clay.

The investigations display the difference between the clay minerals of saline and background soil samples of Seriogovo deposits because of their transformation under the al changes. The expandable layer silicates typical for the soils transformed to the unexpandable dioctahedral soil chlorite. Transformation reactions involve the introduction of non-exchangable hydroxyl-Al polymers into the interlamellar space of pre-existing smectite or vermiculite [1]. The results presented suggest that chlorite was formed diagenetically by prolonged periodic percolation of salt brines through pervious layer silicates.

[1]. Wilson M.J. Clay Minerals, 1999, 34, 15.

\section{MS41 P17}

Crystal Structure and twinning of the new stannide $\mathbf{S r}_{42} \mathbf{L i}_{29} \mathbf{S n}_{74}$. Qinxing Xie, Michael Wörle, Reinhard Nesper. Laboratory of Inorganic Chemistry, ETH Zurich, Switzerland.. E-mail: woerle@,inorg.chem.ethz.ch

Keywords: crystal structures of new compounds, twinning, bond order, tin compounds

Synthesis, physical properties, crystal structure, band structure calculations and bonding analysis of the new stannide $\mathrm{Sr}_{42} \mathrm{Li}_{29} \mathrm{Sn}_{74}$ is reported. The compound crystallizes in the space group P2 $/ \mathrm{m}$. The lattice constants are $\mathrm{a}=15.266(4) \AA$,

$\mathrm{b}=4.930(1) \AA, \mathrm{c}=37.87(1) \AA, \beta=101.592(3)^{\circ}$. All examined crystals were twinned, resulting in an pseudoorthorhombic crystal system The anionic partial structure consists of all-cis Sn-chains, stacked Sn-five-rings which are interconnected by 2-bonded $\mathrm{Sn}$-atoms, and isolated $\mathrm{Sn}$ atoms. (c.f. Fig. 1).

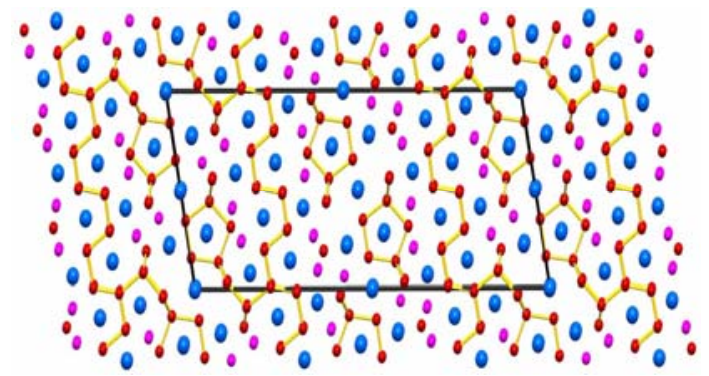

